\title{
Impact of Maternal Obesity on Pregnancy Outcome
}

\author{
Sinha $\mathrm{K}^{1}$, Pandey $\mathrm{S}^{2}$, Das $\mathrm{CR}^{3}$
}

\begin{abstract}
Background: Maternal obesity increases the risk of complications of pregnancy, labor, and neonate.It has been associated with gestational hypertension, eclampsia, pre-eclampsia, gestational diabetes, cesarean delivery, instrumental delivery, abortion, postpartum haemorrhage, puerperal infection and perinatal outcome like macrosomia, still birth and congenital anomaly, birth asphyxia. Aims:To evaluate the effect of maternal obesity on pregnancy outcome. Methods: The hospital based observational study conducted in the department of Obstetrics \& Gynaecology at Nepalgunj Medical College Teaching Hospital Kohalpur between September 2015 to August 2016. Results: Mean age of participant's in the study group was $28 \pm 5.77$ and youngest participant's age was $19 y$ rs and oldest participant was $45 y$ rs. Among the fifty five ladies, 10 were grand multigravida, 30 were multi and 15 were primigravida. $63.6 \%$ delivered by cesarean section, $1.8 \%$ delivered by forceps with episiotomy, $9.1 \%$ delivered by svd, $20 \%$ by svd with episiotomy and $5.5 \%$ by vacuum with episiotomy. Ten participants (18.18\%) had hypertensive disorder during pregnancy. The

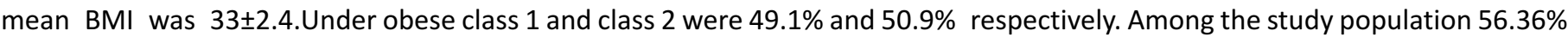
had complications. Mean BMI was 33 minimum being 30 and maximum was 39.81. Regarding body weight maximum was 90 kgs. and minimum was $68 \mathrm{kgs}$ and mean weight being 78kgs. Regarding maternal height maximum was $2.7 \mathrm{~m}^{2}$, minimum was $2.01 \mathrm{~m}^{2}$ and mean was $2.33 \mathrm{~m}^{2}$. Total 7 newborn (13\%) were macrosomic. Among 55 cases 27 fall under obesity class 1 , 11 ladies with complication and among 28 ladies under obesity class 2 , 22 had complications. Conclusion: The obesity has adverse effects on pregnancy outcome both for mother and the foetus.
\end{abstract}

Keywords: Obesity, BMI

\section{INTRODUCTION}

Obesity, at the present time, has become a globally prevalent problem due to change in life style and there is no clear cut definition of obesity.Over weight and obesity is defined as abnormal or excessive fat accumulation that may impair health. The world health organization (WHO) defines "overweight" as a BMI equal to or more than $25 \mathrm{~kg} / \mathrm{m}^{2}$ and "obesity" as a BMI equal to or more than $30 \mathrm{~kg} / \mathrm{m}^{2}$. At the booking visit BMI should be calculated for all pregnant women ideally using pre-pregnancy weight. If pre-pregnancy weight is unknown and BMI being calculated in the first trimester, it is recommended that $1 \mathrm{~kg}$ should be deducted before performing calculation. BMI is usually calculated according to following formula (the Quetlet's index).BMI (Quetlet's index) = weight $(\mathrm{kg}) /$ height $(\mathrm{m})^{2}$ Obesity is also classified into obese class 1 , BMI 30 to $34.9 \mathrm{~kg} / \mathrm{m}^{2}$; obese class 2 , BMI 35 to $39.9 \mathrm{~kg} / \mathrm{m}^{2}$; morbid obesity class $3, \mathrm{BMI} \geq 40 \mathrm{~kg} / \mathrm{m}^{2}$. Obstetrician need to be aware of the maternal and fetal risk associated with obesity. Women should be advised about life style and diet. ${ }^{2}$

\footnotetext{
1. Dr. Kavita Sinha

2. Dr. Subhash Pandey

3. Prof. C. R. Das
}

Address for correspondence:

Dr. Kavita Sinha

Department of Obst. \& Gynae.

Nepalgunj Medical College \& Teaching Hospita

Kohalpur, Banke, Nepal

Email: samesome2002@yahoo.com
The increasing prevalence of obesity also constitutes a major problem in obstetrics practice. Complications associated with obesity in pregnancy are gestational diabetes mellitus, hypertensive disorders and thromboembolic complications during labor are augmentation, early amniotomy, cephalopelvic disproportion, cesarean section and perioperative morbidity and in fetus are macrosomia, shoulder dystocia, small for gestational age, late fetal death and congenital malformation especially neural tube defect. It is well established that the strong association exists between obesity and complications of pregnancy and delivery ${ }^{3}$.

The global obesity epidemic has been escalating over four decades, yet sustained preventive efforts have barely begun, an emerging science that uses quantitative models has provided key insights into the dynamics of this epidemics and enabled researchers to combine evidence and to calculate the effect of behaviors, interventions, and policies at several levels - from Individual to population. Forecasts suggest that high rate of obesity will affect future population, health and economics ${ }^{4}$.

Maternal complication include early miscarriage, pregnancy induced hypertension and preeclampsia, gestational diabetes, thrombo-embolic disease, infections, sleep apnea, prolonged labor and increased risk of interventions like induction of labor, operative delivery, shoulder dystocia and post partum hemorrhage. Perinatal complication include birth defect mainly neural tube defect, macrosomia, still birth, preterm birth and need for intensive care addmission ${ }^{5}$. 
The perinatal mortality increases with increasing maternal pregravid body weight. This would include the increasing frequencies of dizygotic twining, diabetes mellitus, acute chorioamnionitis and major congenital malformations which is final risk responsible for perinatal mortality increase with increasing maternal body weight. Quetlet's index in (pregravid weight $\mathrm{kg} / \mathrm{ht}\left(\mathrm{m}^{2}\right)$ was used to measure relative weight. According to Quetlet's index values: < 20kg/m 2 (thin), $20-24 \mathrm{~kg} / \mathrm{m}^{2}$ (normal), $25-30 \mathrm{~kg} / \mathrm{m}^{2}$ (mildly overweight) and > $30 \mathrm{~kg} / \mathrm{m}^{2}$ (obese) ${ }^{6}$.

The importance of obesity from above studies can well be appreciated regarding the prevalence of obesity and associated maternal and perinatal outcome. This study was aimed to explore the effect of maternal obesity on pregnancy outcome.

\section{MATERIAL AND METHODS}

Hospital based Observational study was conducted from September 2015 to August 2016 at Nepalgunj Medical College Teaching Hospital, Kohalpur, Banke, Nepal. 55 women with Maternal Obesity were included in the study. The pregnant women attending obstetrics department having $\mathrm{BMI} \geq 30 \mathrm{~kg} / \mathrm{m}^{2}$ with single pregnancy were included.

This study was aimed to explore the effect of maternal obesity on pregnancy outcome. All the patients were subjected to routine ANC investigations, ultrasonogram for foetal assessment and Biophysical profile of foetus, maternal scan to rule out gall stone diseases, serology to rule out Hepatitis A, B, $C, E$. and liver function Tests. Patients were admitted in the hospital depending upon the severity of symptoms, state of liver and period of gestation at the time of presentation. Babies were evaluated for features of prematurity, weight, meconium aspiration at Birth and for any other complications.

\section{RESULT}

\section{Distribution according to age group}

The mean age of participant's in the study group was $28 \pm 5.77$. The youngest participant's age was $1.9 \mathrm{yrs}$ and oldest participant was 45 years.

\begin{tabular}{|c|c|c|}
\hline AGE IN YEARS & FREQUENCY & PERCENTAGE (\%) \\
\hline $15-20$ & 2 & 3.6 \\
\hline $21-25$ & 22 & 40 \\
\hline $26-30$ & 15 & 27.3 \\
\hline$\geq 31$ & 16 & 29.1 \\
\hline TOTAL & 55 & 100 \\
\hline
\end{tabular}

Table I: Distribution according to maternal age
Distribution according to gravidity:

Among study group of 55 ladies, 10 of them were grand multigravida, 30 were multi and 15 were primigravida.

\begin{tabular}{|c|c|c|}
\hline GRAVIDITY & FREQUENCY & PERCENTAGE \\
\hline GRAND MULTI & 10 & 18.2 \\
\hline MULTI & 30 & 54.5 \\
\hline PRIMI & 15 & 27.3 \\
\hline TOTAL & 55 & 100 \\
\hline
\end{tabular}

Table II: Distribution according to gravidity

Distribution of patient according to mode of delivery: Among study population $63.6 \%$ delivered by cesarean section, $1.8 \%$ delivered by forceps with episiotomy, $9.1 \%$ delivered by svd, $20 \%$ by SVD with episiotomy and $5.5 \%$ by vacuum with episiotomy

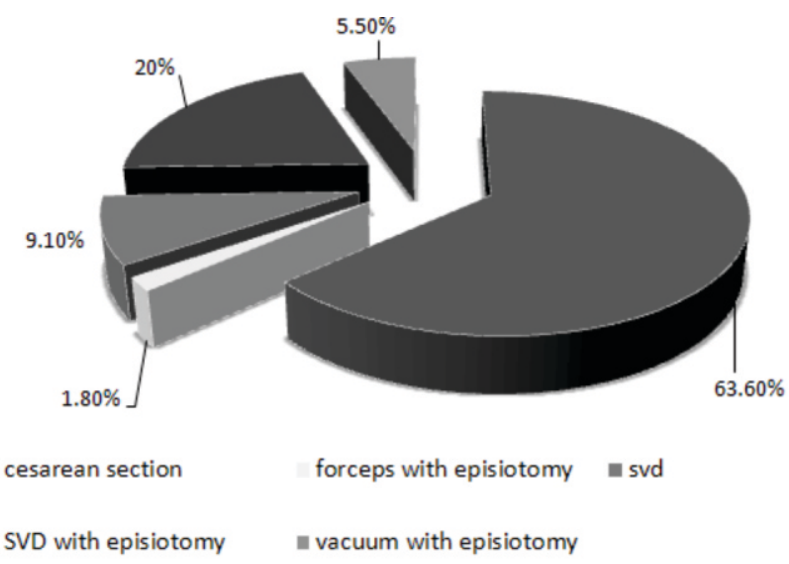

Figure1:Distribution according to mode of delivery

Distribution of patients according to the gestational age: In this table, it shows that study participants $1.8 \%$ pregnancy were preterm, $70.9 \%$ pregnancy were term and $27.3 \%$ pregnancy were post-term.

\begin{tabular}{|c|c|c|}
\hline GESTATIONAL AGE & FREQUENCY & PERCENTAGE \\
\hline PRETERM & 1 & 1.8 \\
\hline TERM & 39 & 70.9 \\
\hline POST TERM & 15 & 27.3 \\
\hline TOTAL & 55 & 100 \\
\hline
\end{tabular}

Table III: Distribution according to maternal age 


\section{Association of hypertensive disorder in pregnancy with}

BMI:

Regarding hypertensive disorder in pregnancy 10 participants (18.18\%) had hypertensive disorder during pregnancy. Statistically significant difference was not observed between maternal obesity and hypertensive disorder during pregnancy as shown in Table IV.

Incidence of fetal outcomes

Among the study population $56.36 \%$ had complications. There was statistically significant difference observed between maternal obesity and fetal complications as shown in table $\mathrm{V}$.

\section{Determination of baby birth weight}

Seven newborn (i.e $13 \%$ ) babies were macrosomic. There was statistically significant difference observed between maternal obesity and baby birth weight. The rate of macrosomia increases with increase in maternal obesity.

\section{Maternal complications and BMI}

Among 55 cases 27 fall under obesity class 1, 11 ladies with complication and among 28 ladies under obesity class 2,22 had complication. This study shows that pregnancy related complications were more with obesity class 2 . There was statistically significant difference observed between maternal obesity according to class with the pregnancy related maternal complications as shown in table VII.

\begin{tabular}{|c|c|c|c|c|c|}
\hline \multirow{2}{*}{ Hypertension } & \multicolumn{2}{|c|}{ BMI } & \multirow{2}{*}{ Total } & \multirow{2}{*}{ p Value } & \multirow{2}{*}{ OR (95\% Cl) } \\
\cline { 2 - 4 } & Class 1 & Class 2 & & \multirow{2}{*}{0.857} \\
\hline Normal BP & 30 & 15 & 45 & 0.839 & $(0.194-3.795)$ \\
\hline Hypertension & 7 & 3 & 10 & & \\
\hline Total & 37 & 18 & 55 & & \\
\hline
\end{tabular}

Table IV: Association of hypertensive disorder in pregnancy with BMI

\begin{tabular}{|c|c|c|c|c|c|}
\hline \multirow{2}{*}{ BMI } & \multicolumn{2}{|c|}{ Fetal Complications } & \multirow{2}{*}{ Total } & \multirow{2}{*}{ p Value } & \multirow{2}{*}{ OR (95\% Cl) } \\
\cline { 2 - 3 } & Present & Absent & 27 & \multirow{2}{*}{0.379} \\
\hline Class 1 & 12 & 15 & 28 & $(0.126-1.136)$ \\
\hline Class 2 & 19 & 9 & 55 & & \\
\hline Total & 31 & 24 & & & 0.04 \\
\hline
\end{tabular}

Table V: Incidence of fetal complication in relation to maternal obesity

\begin{tabular}{|c|c|c|c|c|c|}
\hline \multirow{2}{*}{$\begin{array}{c}\text { Baby } \\
\text { Birth Weight }\end{array}$} & \multicolumn{2}{|c|}{ BMI } & \multirow{2}{*}{ Total } & \multirow{2}{*}{ P Value } & \multirow{2}{*}{ OR (95\% Cl) } \\
\cline { 2 - 3 } Macrosomic $\geq 4 \mathrm{~kg}$ & 7 & - & 7 & \multirow{2}{*}{0.048} & 1.6 \\
\hline Not macrosomic $<4 \mathrm{~kg}$ & 30 & 18 & 48 & $(1.285-1.992)$ \\
\hline Total & 37 & 18 & 55 & & \\
\hline
\end{tabular}

Table VI: Relationship between baby birth weight and maternal obesity

\begin{tabular}{|c|c|c|c|c|c|}
\hline \multirow{2}{*}{$\begin{array}{c}\text { Maternal } \\
\text { complication }\end{array}$} & \multicolumn{2}{|c|}{ BMI classification } & \multirow{2}{*}{ Total } & \multirow{2}{*}{ V Value } & \multirow{2}{*}{ OR (95\% Cl) } \\
\cline { 2 - 3 } & Class 1 & Class 2 & & \multirow{2}{*}{0.006} & 0.188 \\
\hline Present & 11 & 22 & 33 & $(0.057-0.613)$ \\
\hline Absent & 16 & 6 & 22 & & \\
\hline Total & 27 & 28 & 55 & & \\
\hline
\end{tabular}

Table VII: Association between maternal complications with obesity class 


\section{Distribution of patients according to the obesity class:}

Here the mean BMI was 33 and standard deviation (s.d. \pm ) was 2.4 among the study participants $49.1 \%$ were under obese class 1, 50.9\% were under obese class 2 .

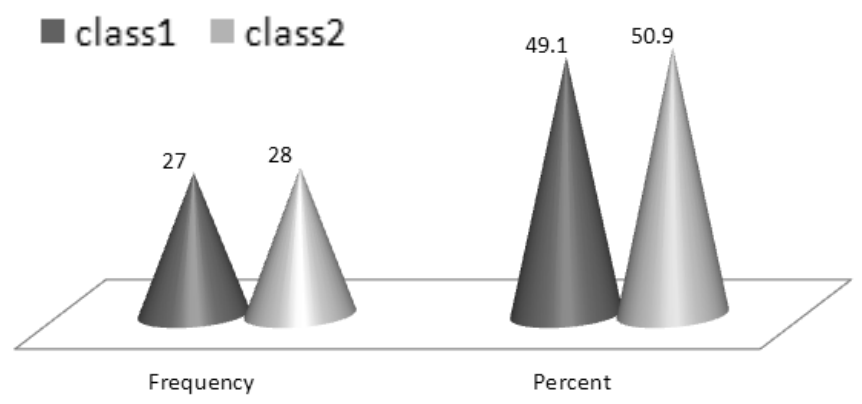

Figure 2: Distribution according to obesity class

\section{DISCUSSION}

This study was conducted to explore the relationship between maternal obesity and pregnancy outcome. Obesity is reaching pandemic proportion worldwide. It increasingly being recognized as a risk factor during pregnancy. The mean of maternal age for the participants mothers in the current study was 28 years and the youngest participant age is 19 years and oldest participant age is 45 years about $70 \%$ participants were less than 30 years and standard deviation (S.D.) is 5.77. In this study, maximum number of women $54.5 \%$ were multigravida and $27.3 \%$ were primigravida only $18.2 \%$ constituted grand multigravida. Mendes MS and Matozinhos FP $(2006)^{7}$ recorded minimum age was 15 years and maximum being 40 years mean was 27.5 years which is almost coinciding with present study while Goons $(2013)^{8}$, obesity and overweight status were found to be significantly associated with age, women aged 31 and above were more likely to be obese which is not coinciding with present study where about $70 \%$ participants were less than 30 years.

The prevalence of hypertension disorder in pregnancy is $18.18 \%$, in the current study among the total participants. While Mandal D et al. (2011) ${ }^{9}$ the rate of hypertensive disorder in pregnancy is $13 \%$ which is lower than current studies. Dietary habits and environmental factor might be counted as a factor for high incidence of gestational hypertension. The target population of the current study was obese pregnant women.So their BMI are 30 and over and the average weight was $78 \mathrm{kgs}$ and height is $2.4 \mathrm{~m}^{2}$ and average BMI was 33 .

The obesity was classified as Class I obesity $=49.1 \%$ and Class II obesity $=50.9 \%$ which is similar to Kabiru W, Raynor B $(2004)^{10}$ $49.8 \%$ under moderate obesity. In Sebrine NJ et al $(2001)^{11}$, $24.3 \%$ study population come under moderate Obesity and 9.6\% under very obese group but while our study maximum women come under moderate obesity i.e. 50.9\%. Maternal obesity is becoming a global health problem affecting health of both mother and child. Optimization of weight prior to conception should be the goal. BMI should be calculated in all pregnant women ideally using the pregnancy weight of women with $\mathrm{BMI}$ over 30 to be considered to be higher risk.

The delivery of infants through cesarean section was $63.6 \%$, Spontaneous vaginal delivery with episiotomy is $20 \%$, spontaneous vaginal delivery is $9.1 \%$ and instrumental delivery was $7.3 \%$. Chauhan et al. $(2001)^{12}$, delivery through cesarean section was $57 \%$, vaginal birth was $43 \%$. As compared to present study the cesarean section rate is slightly lower and rate of vaginal birth is higher in their series. While Mandal et al. $(2011)^{9}$, the rate of cesarean section in their study population was $36 \%$ and the instrumental delivery rate was $12.32 \%$ but in present study instrumental delivery rate was found to be $7.3 \%$. So the rate of cesarean section was lower and the instrumental delivery rate was higher in their study as compared with present study.

The different study like Aimukhametova $\mathrm{G}$ et al. $(2012)^{13}$ the rate of preterm delivery $<37$ weeks of gestations is $8.3 \%$ and $>37$ weeks of gestation was $91.7 \%$ and the incidence of fetal macrosomia is $23.5 \%$ and intra uterine growth restriction is $5.9 \%$. According to the current study fetal distress is common in pregnancy with obesity followed by big baby, the rate of birth asphyxia was $3.6 \%$, any fetus with gross congenital anomaly was not detected in the study group.So increase in BMI brings lots of complications to mother as well as to the fetus. Finally current study shows that $13 \%$ of babies were macrosomic having birth weight $\geq 4 \mathrm{kgs}$.

The current study shows that nonprogress of labor is more common complication faced by pregnant lady with obesity followed by cephalopelvic disproportion which are major cause of increasing cesarean section rate in obese and the rate of postpartum hemorrhage is $1.8 \%$. According to Paiva LV and Nomura RM $(2012)^{14}$ the rate of wound infection was $16.7 \%$ which was very high. In Sebire NJ et al.(2001) ${ }^{11}$ the rate of post partum hemorrhage was $18 \%$ which is almost ten times higher than the present study. Maternal complications increases with increase in BMI. Excessive fat accumulation hinder wound healing and provide environment for growth Of organisms and uterine muscle do not contract efficiently with presence of obesity so rate of post partum hemorrhage and wound infection is high with increase in BMI.

\section{CONCLUSION}

Obesity is a serious public health problem wordwide. It has adverse effects on pregnancy outcome both for mother and the fetus. Obstetricians need to be aware of maternal and fetal risk associated with obesity and the client should be given appropriate dietary and life style advice. 


\section{REFERENCES}

1. World Health Organization. Obesity and overweight. WHO Fact sheet No. 311.September 2006.

2. Dixit A and Girling JC. Obesity and pregnancy. J ObstetGynecol 2008;28:14-23.

3. Hall LF, Neubert G. Obesity and Pregnancy. ObstetGynecolSurv 2005;60:253-60.

4. Gortmaker SL, Swinburn BA, Levy D, Carter R, Marsh T, Huang T, et al . Changing the future of obesity. Lancet 2011;378:838-47.

5. Cedergren MI. Maternal morbid obesity and pregnancy and the risk of adverse pregnancy outcome. ObstetGynecol 2004;103(2):219-24.

6. Naeye RL. Maternal body weight and Pregnancy outcome. Am J ClinNutr 1990;52:273-9.

7. Mendes MS, Matozinhos FP, Miranda JJ, Villamor E, Velasquez MG .Maternal obesity and fetal deaths. BMC pregnancy and child birth 2014;14(5):1471-2393.

8. Goon S. Prevalence of obesity among Bangladeshi pregnant women at their first trimester of pregnancy. CAJGH 2013;2(2):114.

9. Mandal D, Mandal S, Rakshit A, Dey RP, Biswas SC, Banerzee A. Maternal obesity and pregnancy outcome. J Assoc Physicians India 2011;59:486-9.

10. Kabiru W, Raynor B. Obstetric outcomes associated with increase in BMI category in pregnancy. Am J ObstetGynaecol 2004;191:928-32.

11. Sebire NJ, Jolly M, Harris JP, Wadsworth J, Beard RW, et al. Maternal obesity and pregnancy outcome: a study of 287,213 pregnancies in London. Int J ObstetRelatMetabDisord. 2001;25(8):1175-82.

12. Chauhan SP, Magnan EF, Carol CS, Barilleaux PS, Scardo JA, Martin JN. Mode of delivery for the morbidly obese with prior caesarean delivery, vaginal delivery versus repeat caesarean section. Am J ObstetGynecol 2001;185:349-54.

13. Aimukhametova $\mathrm{G}, \mathrm{Ukybasova} \mathrm{T}$, Hamidulina $\mathrm{Z}$, Zhubanyshova KY, Rashid HO, Yoshida Y. The impact of maternal obesity on mother and neonatal health.Nagoya. J Med Sci 2012;74:83-92.

14. Paiva LV, Nomura RM, Dias MC ,Zugaib M. Maternal obesity in high risk pregnancies and postpartum infectious complications. Rev Associate Med Bras 2012;58(48):453-8. 